\title{
ARDUINO BASED AUTOMATIC GATE CONTROL USING BLUETOOTH
}

\author{
Atul .V. Kamble ${ }^{1}$, Sayali. S. Taralekar ${ }^{2}$, Ashwini .P. Kharat ${ }^{3}$, Pradnya .P. Shinde ${ }^{4}$ \\ ${ }^{1}$ M.E. Student, VLSI and Embedded System, ADCET, Ashta, Maharashtra, India \\ ${ }^{2}$ B.E. Student, Electronics \& Telecommunication, ADCET, Ashta, Maharashtra, India \\ ${ }^{3}$ B.E. Student, Electronics \& Telecommunication, ADCET, Ashta, Maharashtra, India \\ ${ }^{4}$ B.E. Student, Electronics \& Telecommunication, ADCET, Ashta, Maharashtra, India
}

\begin{abstract}
In the developing countries like India accidents at the railway crossing are increasing day by day. The main reason of these accidents is negligence of train drivers and gatekeepers. So this system is mostly designed to help railway. This system is also useful for various industries for safety purpose. After all security matters more. It includes opening and closing of gate by the use of Arduino Bluetooth app in our mobile. Our system includes Bluetooth module connected to Arduino. When the connection is established between Bluetooth module and Arduino Bluetooth app the gate can be controlled. Our system mostly concentrates on the security. The gate is connected to servomotor. As the servomotor will rotate the gate will accordingly rotate. There is requirement of such system in restricted areas like toll collection, Hospitals and also Schools / Institutes.
\end{abstract}

Keywords: Servomotor, Arduino, Bluetooth module, Arduino Bluetooth app. ***.

\section{INTRODUCTION}

This system contracts with intellect of train with automatic gate controlling to flee accidents at Railway crossings. The main approach of system is, depending on entrant and take off of the train near railway crossing. The crossing gate will automatically open and close by displaying signals like Red or Green. When the train drawing near railway crossing, the gate will close and displays Green signal for train. The system uses RF Transceiver, IR Sensor, Microcontroller, DC Motor, Relay etc. [1]

It is not possible to administer every crossing. So there are many neglected railway crossings and the case is more observed in rural and remote places. This system of railway network cannot be managed manually. Automatically Operatable Level Crossings is a system which does not desire any human to be present. Everything is controlled with the help of motors. It also reduces human errors. This system is operated automatically by sensors. In this research IR sensors are used and fixed them at certain distance from each other. To avoid the confusion between trains and other things sensors are organised in AND logic. It is stable and also reliable. [2]

Automatic gate control system is an organisation of components which sense the entrant of the vehicle and make the gate open and close automatically. As a vehicle enters at the crossing, the sensors which are fixed at a certain distance from the gate detect the avenue of vehicle and controls the operation of the gate. To flee the accidents, sensors fixed at specific distance from the gate detect the take off of the train. The signal about the take off is transmitted to microcontroller, which operates the motor and opens the gate. The time required to close the gate is less as compared to the human operated gates. Reliability is high, as there are no human made errors. [3]

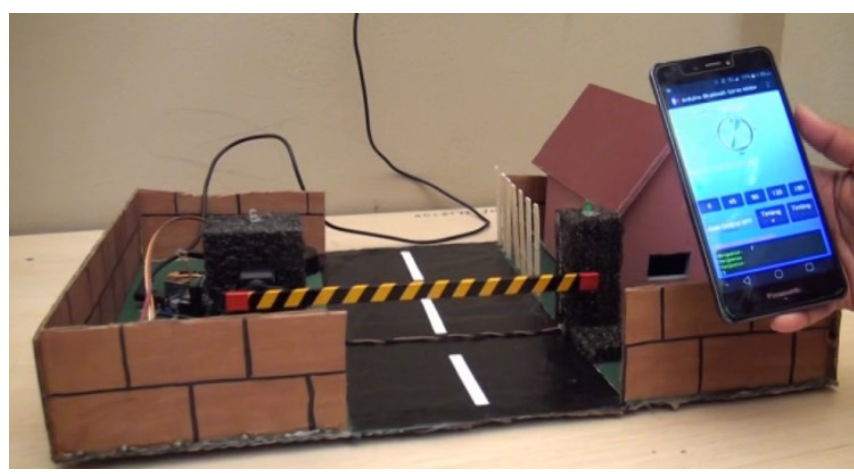

Fig 1:- Automatic gate control system using bluetooth [front view]

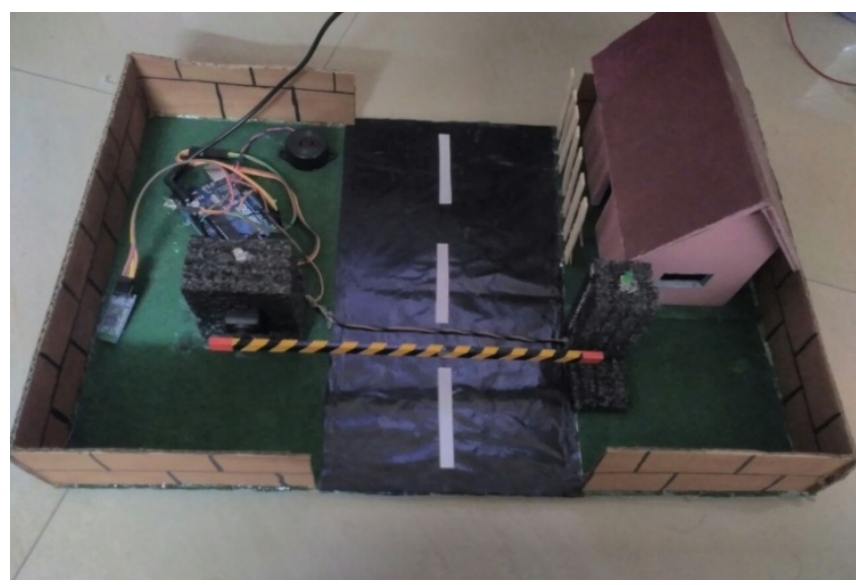

Fig 2:- Automatic gate control using bluetooth [top view]

Fig 1 and Fig 2 shows actual demonstration model of the project in front view and top view. In fig 1 it is shown that the gate is controlled by Arduino bluetooth app in mobile. 


\section{PROBLEM DEFINATION}

There are various automatic gate control systems evolved depending upon the sensors. Although these sensors reduce the human errors their drawback is security.

So, our system will reduce human errors as well as provide security as gate will be controlled by Arduino bluetooth app in our mobile.

In various industries as well as homes there is not only requirement of automatic gate control system but also security. Our system allows to pass vehicles from gate which have known password of bluetooth connected to gate.

\section{METHODOLOGY}

Fig 3:- shows conceptual block diagram of Automatic gate control system which consists of bluetooth module connected to Arduino board, Arduino bluetooth app in mobile, Arduino uno and Servomotor. Gate is connected to the servomotor. The main control unit of our system is Arduino.

The connection is established between bluetooth module and android bluetooth app in mobile. Different angles are available in app so that servomotor (gate) is rotated in required angle as shown in fig 3 .

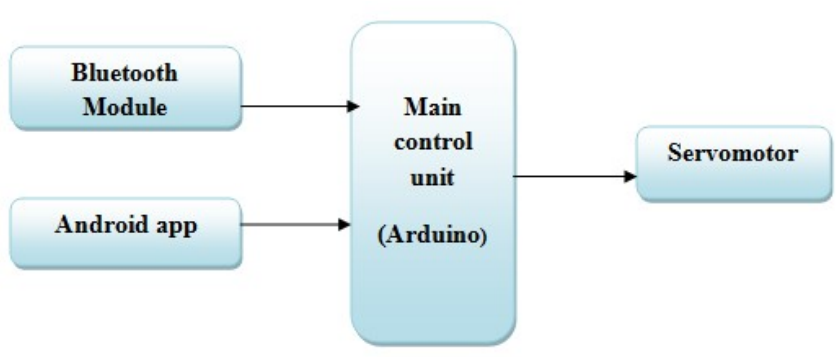

Fig 3:- Conceptual block diagram of Automatic gate control system

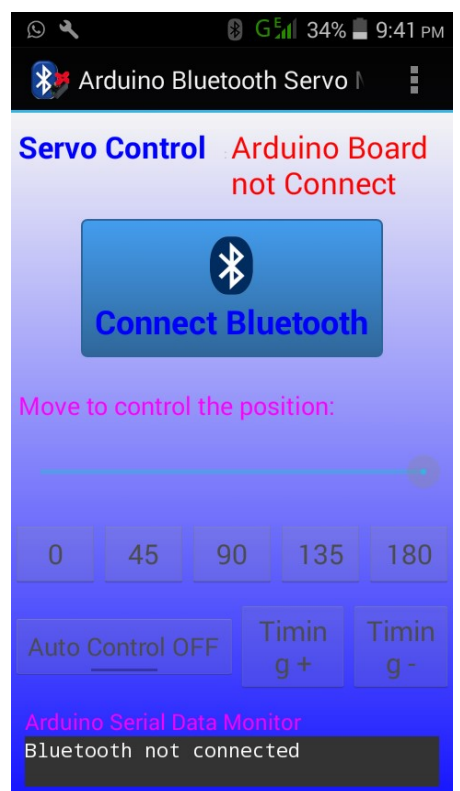

Fig 4:- Arduino bluetooth app in mobile

\section{APPLICATIONS}

- This system can be implemented at railway crossings so that gate can be controlled by using bluetooth to avoid accidents due to human error.

- Our system is Economical.

- Also can be used in industries and homes where high security is required.

- There is requirement of such gate in restricted areas like Toll collection, School and colleges to avoid accidents.

\section{CONCLUSION}

Our proposed system is economical, Easy to design and improves standard of living and is effective as well as safe. This system is most important in the sense of security for homes, Railways and industries, Schools, Colleges and various Institutes.

\section{ACKNOWLEDGEMENT}

We would like to express our sincere and special thanks to Prof. M.N.CHAVAN [Annasaheb Dange college of Engineering and Technology, ASHTA] for her advice which helped us writing this review paper.

\section{REFERENCES}

[1]. International Journal of Science and Research (IJSR) Volume 3 Issue 3, March 2014, Intelligent System for Train Engine with Automatic Gate Controlling using Wireless Technology in Bangladesh (Kawshik Shikder).

[2]. Shivani Madhok and et.al "Sensor Network Based Automatically Opertable Barricadeson Public Railway Crossing" Gyancity Journal of Engineering and Technology Vol.1 No.2 July 201521 ISSN: 2456-0065

[3]. Saifuddin Mahmud and et.all "Automated Railway Gate Controlling System" International Journal of Computer Trends and Technology (IJCTT) - volume 27 Number 1 September 2015.

\section{BIOGRAPHIES}

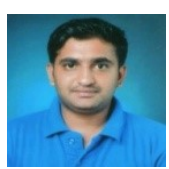

Atul .V. Kamble, [ M.E. VLSI \& Embedded system] ADCET,ASHTA

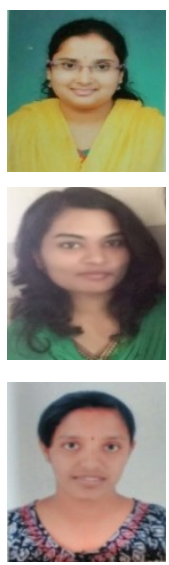

Sayali. S . Taralekar, [B.E Electronics \& telecommunication] ADCET,ASHTA

Ashwini .P. Kharat, [B.E Electronics \& telecommunication] ADCET,ASHTA

Pradnya .P. Shinde, [B.E Electronics \& telecommunication] ADCET,ASHTA 